\title{
Article \\ Real Business Applications and Investments in Blockchain Technology
}

\author{
Oscar Lage $^{1,2, *\left(\mathbb{C}, \text { María Saiz-Santos }^{2} \text { () and José Manuel Zarzuelo }\right.}{ }^{2}$ \\ 1 TECNALIA, Basque Research and Technology Alliance (BRTA), Parque Científico y Tecnológico de Bizkaia \\ \#700, 48160 Derio, Spain \\ 2 Faculty of Economics and Business Administration, The University of the Basque Country, \\ Av. Lehendakari Aguirre, 83, 48015 Bilbao, Spain; maria.saiz@ehu.eus (M.S.-S.); \\ josemanuel.zarzuelo@ehu.eus (J.M.Z.) \\ * Correspondence: Oscar.Lage@tecnalia.com
}

Citation: Lage, O.; Saiz-Santos, M.; Zarzuelo, J.M. Real Business

Applications and Investments in Blockchain Technology. Electronics 2022, 11, 438. https://doi.org/ 10.3390 /electronics 11030438

Academic Editor: Ping-Feng Pai

Received: 18 December 2021

Accepted: 29 January 2022

Published: 1 February 2022

Publisher's Note: MDPI stays neutral with regard to jurisdictional claims in published maps and institutional affiliations.

Copyright: (C) 2022 by the authors. Licensee MDPI, Basel, Switzerland. This article is an open access article distributed under the terms and conditions of the Creative Commons Attribution (CC BY) license (https:// creativecommons.org/licenses/by/ $4.0 /)$.

\begin{abstract}
This paper provides an empirical study to identify the objective of companies that are currently investing in adopting blockchain technologies to improve their processes and services. Unlike other studies based on the theoretical potential application of blockchain technology in different sectors, the main objective of this paper is to analyze real projects and investment of companies in blockchain technology. More than 100 blockchain projects from different sectors were examined with the aim of extracting the perceived applicability and business value of blockchain technology by managers, customers, and partners. We identified the most demanded business value and functional properties in each sector and company size, as well as the relationship between the properties that are demanded together. This article assesses the main functional values attributed to blockchain, highlighting those really appreciated by companies that invest in them and identifying new applications of blockchain technology in different sectors, and generating organizational change. The article reveals that, as expected, significant deviations are already occurring between theoretical applications identified in the literature and those finally adopted by the industry.
\end{abstract}

Keywords: blockchain; IT business value; technology innovation; technology strategy; organizational transformation

\section{Introduction}

The birth of bitcoin [1] at the end of 2008 was much more than the beginning of the first decentralized cryptocurrency. The technology designed to support bitcoin cryptocurrency would later be called blockchain and give rise to a new family of decentralized technologies. Blockchain is a distributed peer-to-peer architecture that introduces major disruptions to traditional business by decentralizing governance through the creation of a secure design that does not require trusted third parties to establish transactional relationships between two parties.

However, it was not until 2014-2016 when researchers began to identify the benefits of blockchain technology for different industries. Financial services [2,3], healthcare [4,5], energy [6,7], and public administrations [8] were some of the first industries to analyze the theorical applications of blockchain technology, and in general of Distributed Ledger Technologies (DLTs).

According to $83 \%$ of C-suite executives [9], their companies will lose competitive advantage if they do not adopt blockchain. Leaders are increasingly investing in blockchain and digital assets as one of the top five strategic priorities, with $66 \%$ forecasting investment of USD 1 million or more in the next months, nearly $40 \%$ of them have blockchain in production. 
There are several overall reviews regarding potential or theorical blockchain-based applications (Table 1). However, what is the real functional value provided to the companies? What specific business needs can be addressed by blockchain?

Table 1. Applications investment by company size (percentages).

\begin{tabular}{ll}
\hline Source & Research Objective(s) \\
\hline Seebacher et al. [10] & Systematic literature review of blockchain applicability. \\
\hline Tama et al. [11] & $\begin{array}{l}\text { Identification of the main areas of potential applicability of } \\
\text { blockchain technology. }\end{array}$ \\
\hline Hawlitschek et al. [12] & $\begin{array}{l}\text { Evaluation of blockchain from the perspective of its } \\
\text { potential application in the shared economy. }\end{array}$ \\
\hline Casino et al. [13] & $\begin{array}{l}\text { Systematic literature review of blockchain applicability. } \\
\text { Elaborate on a taxonomy of blockchain-based applications } \\
\text { in several sectors. }\end{array}$ \\
\hline Laroiya et al. [14] & $\begin{array}{l}\text { Overview of the different uses and applications of } \\
\text { blockchain technology. }\end{array}$ \\
\hline Perera et al. [15] & $\begin{array}{l}\text { Identification of potential applications, characteristics, and } \\
\text { adoption drivers of blockchain in the construction industry. }\end{array}$ \\
\hline Ko et al. [16] & $\begin{array}{l}\text { Identification of potential blockchain applications in the } \\
\text { manufacturing industry. }\end{array}$ \\
\hline
\end{tabular}

Seebacher et al. [10] conducted one of the first systematic reviews of the literature analyzing the common characteristics identified in 32 articles that examined potential uses of the technology. The two main features identified in the work are trust and the decentralized nature of the technology. Concerning trust, three pillars were identified: (i) transparency that favors interaction and reduces friction between parties, (ii) data integrity through the verification of transactions by peers and the use of cryptography, and finally (iii) the immutability of agreed transactions. In terms of the decentralized nature, three other characteristics were highlighted: (i) the privacy and pseudo-anonymity of the participants, (i) their reliability through data redundancy and their consequent potential for automation, and (iii) its versatility. These characteristics allow the understanding of the two fundamental pillars of any blockchain use case. Therefore, trust and decentralization, to a higher or lower degree, depending on the network typology, will be present in the following reviews.

Tama et al. [11] identify in their analysis four main areas of potential applicability of blockchain technology. The first area is financial services, analyzing the impact of cryptocurrencies on the financial market and the decentralization of their services. The second is the healthcare sector, which highlights the potential of blockchain technology to facilitate the interoperability of electronic health records, as well as patient self-governance over their data. Regarding the third category, "Business and industry", diverse applications were found: (i) the use of Distributed Autonomous Corporation (DAC) as an entity to offer services between IoT devices, (ii) the traceability related to the supply chains in the food sector, or (iii) the use of blockchain tokens to generate an edge computing market. Finally, under the name "Other Implementations", other hypothetical uses of blockchain technology were identified, such as the digital right management system, reputation system, digital content distribution system, WIFI authentication, and IoT security.

Hawlitschek et al. [12] evaluate blockchain from the perspective of its possible applicability in the shared economy, and identify that the conceptualization of trust, one of the two main basic characteristics of the sharing economy according to the authors, differs between the blockchain contexts and the collaborative economy literature. However, according to the authors blockchain can play a key role in the future of the shared economy.

Casino et al. [13] elaborated on a taxonomy of blockchain-based applications after the study of 260 articles and 54 reports of the grey literature. This taxonomy identifies 
the following potential application domains: financial applications, integrity verification, governance, Internet of Things and distributed device management [17], health, education, privacy and security, business and industry, and data management.

Laroiya et al. [14] analyze the application of blockchain in various use cases: financial services, banking, insurance, healthcare, voting, real estate, supply chain, music industry, and identity management. After their study, the authors determined that industries are adopting blockchain for its transparency, security, inexpensiveness, security, as well as for creating a better contribution economy, preventing payment scams and its ability to perform financial transactions in minutes.

Perera et al. [15] focus their study on the applicability of blockchain technology in the construction industry. The authors identify 12 characteristics of blockchain that potentially bring value to this specific sector, and six drivers for its adoption. However, the authors point out that data privacy, data storage and querying, scaling difficulties, and the need for high computational power are barriers that may hinder the adoption of the technology in this sector.

Ko et al. [16] identify that real-time transparency and the reduced costs achieved by blockchain technology can help a manufacturing firm to compete in the market by increasing its profits. The authors conclude that blockchain enables the manufacturing industry to reduce surveillance and networking costs, but that it will require an investment for deployment. The authors show that this deployment investment would pay for itself in a very short time.

These authors also point out that although the literature attempts to propose blockchain as a panacea it should not be used in every case. In particular, Seebacher et al. [10] remarked that for further research it would be interesting to explore the contribution of blockchain in non-theorical projects by performing an empirical analysis of real cases. They suggested that significant deviations are expected between theoretical applications and those finally adopted by industry.

This research is in the same spirit of the research conducted by the previous authors, that is, our aim is to analyze real projects in which companies have invested, to understand and measure the perceived value of blockchain technology in business. Everything is based on a systematic review of all the blockchain innovation projects that Tecnalia has carried out for private companies and public administration.

The work is organized as follows. Section 2 presents the methodological approach used to carry out the research. Section 3 describe the results and the contribution, explaining the benefits of blockchain for companies and the statistical impact of each one, which is expected to help researchers to identify new projects and applications of this technology. Finally, Section 4 ends with the presentation of the most relevant conclusions, trends, and further research lines.

\section{Materials and Methods}

A mixed research method combining a qualitative and quantitative analysis was carried out to answer our research question: "What is the real business value and functional properties of blockchain for companies regardless of the sector and application?". Therefore, a qualitative analysis of actual project documentation was combined with the statistical analysis of the database created from the qualitative analysis.

The starting point was the information associated with blockchain projects carried out by Tecnalia's cybersecurity and blockchain research group. To endorse the significance of this information it should be noted that Tecnalia is a leading research and technological development center in Europe. It is the first private Spanish organization in contracting, participation, and leadership in the European Horizon 2020 and ranked second in European patent applications.

To obtain the information, 104 blockchain-related contracts in the period from 2017 to 2020 were selected from the corporate ERP (Enterprise Resource Planning) software. The information on these contractual agreements was extracted in a spreadsheet and 
those contracts belonging to the same project in which several entities were involved were grouped together. There were 55 individual projects and 12 consortium projects with a maximum of seven partners and an average of 4.08 research participants per consortium.

The projects widely reflect the main economic sectors, so we consider it a broad enough sample to obtain significant results. Figure 1 shows the representation and investment by sector in the analyzed sample (in percentages).

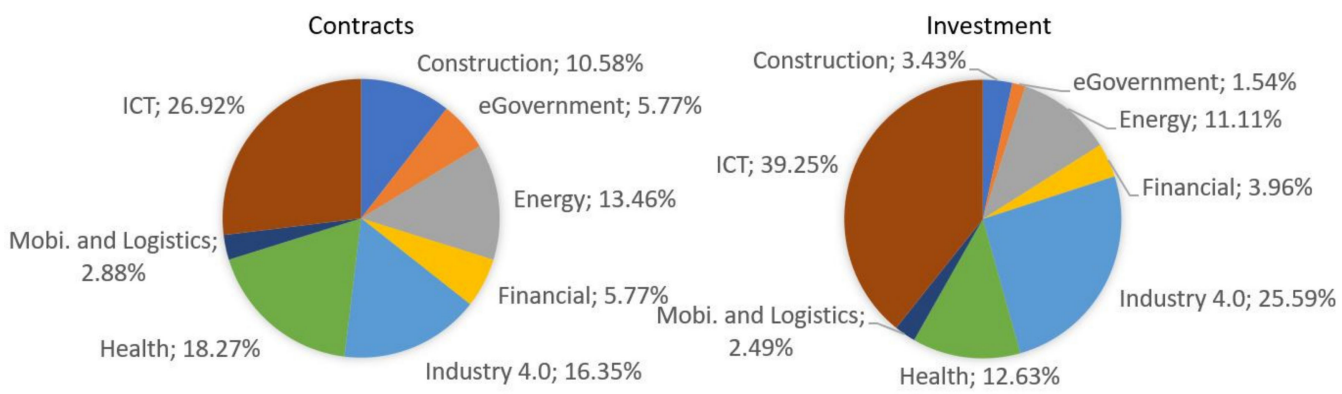

Figure 1. Blockchain investment distribution by sector.

Regarding the relative impact on the investments, it can be observed how the ICT (Information and Communication Technologies) projects are positioned as the ones with the largest budget, surely because this sector has understood, and demanded, the blockchain technology before others.

Concerning the size of the company, Figure 2 shows the distribution of investments according to company size. As can be seen, medium-sized companies are the ones that prevail both in terms of the number of contracts and their investment.

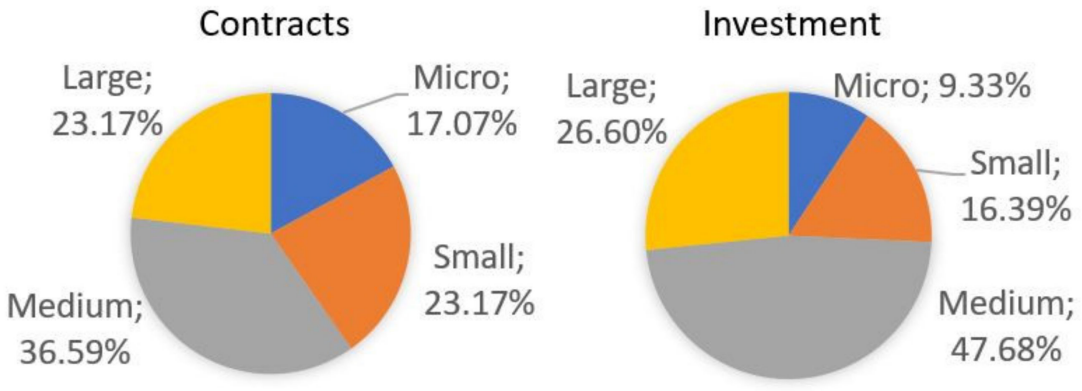

Figure 2. Blockchain investment distribution by company size.

The next step after the creation of the database was to compile the documentation of contracts, project reports, and consortium agreements. In all the documents there was a section that expresses, under different titles and denominations, the needs of the customer or consortium, the opportunity, and the challenge faced by the project using blockchain in combination with different technologies. A qualitative content analysis of the documentation was carried out to identify the keywords that define the needs that motivated the investment.

Thus, to obtain the list of benefits of the technology, a thorough reading of the project documentation was carried out and all the keywords were noted down in the project documentation. Once the keywords expressing the needs covered by blockchain technology had been isolated, they were standardized and grouped together, resulting in 12 values or applications for which companies are investing in blockchain, which we analyze in the following section. Finally, we performed an analysis of the relationships between the 12 benefits using hierarchical clustering, the results of which are presented in Section 3.3. 


\section{Results}

The different benefits identified in the research are discussed below, starting with a definition of each perceived value, continuing in the following sections with an understanding of the impact of each of them in the different sectors or company sizes, and finally with an analysis of the relationships between them.

\subsection{Perceived Value of Blockchain Technology}

\subsubsection{Decentralization of Processes}

Decentralization of processes is one of the most obvious benefits of blockchain technology because of its distributed architecture and its ability to create reliable peer-topeer relationships without the need for a trusted third party to intermediate between the parties [18].

Blockchain enables the management of business-to-business processes in a decentralized way, allowing all parties to directly participate in the management of business processes. Blockchain makes it possible to audit each process, as well as its compliance with the business rules established by the community in the blockchain network [19].

In several of the evaluated projects, there was a group of participants who wanted to establish a common management of processes, however, for political or economic reasons, they had decided not to implement it [20]. These participants considered that creating a third-party organization, or relying on an existing one, was more costly than the benefit of joint transactions. They also did not consider that all of the processes could be managed by one of the community participants, as this would give that participant huge power by managing the information and processes of the rest of the partners. With blockchain technology, these types of communities have been able to create an application so that they can interact with each other in a decentralized way.

In other cases, the centralization of the decision making was a risk and a single point of failure/attack that could cause a great impact on the ecosystem, so they have found blockchain to be a solution. Furthermore, in other projects, geopolitical interests and the need for decision-making not to be "implemented" in a single territory, or continent, were combined to give confidence to the parties in adopting the system [21]. For others, the purpose was to create a digital ecosystem between devices that interact with each other in a decentralized manner, closely related with M2M and Machine Economy.

Finally, this decentralization of governance was the way to reach the decentralization of business models as will be seen in the following section.

\subsubsection{Decentralization of Business Models}

The academic literature is now starting to reflect the decentralization of business models in studies such as [22-24]. The research has determined how companies want to disrupt current business models, especially platform business models [25].

The internet has enabled the creation of new business models based on digital platforms, such as Airbnb and Uber, that allows them to create ecosystems in which some participants offer products/services, while others require such products/services, so they use the platform to establish contact. Currently, countless companies are trying to be the Uber for $\mathrm{X}$ or $\mathrm{Y}$ of their ecosystem, to create the digital platforms that respond to a specific need and charge for the intermediation between parties.

Precisely the business model that companies have been trying to adopt in recent years, the platform business model, is the one that companies in the study try to destroy. An open and free blockchain application can offer to the suppliers and demanders of products/services a very similar service to the current digital platforms. In addition to the analyzed projects, it is possible to find initiatives such as OpenBazaar that aim to disrupt and be a decentralized and free alternative of companies such as eBay or AliExpress that follow the platform business model [26]. 


\subsubsection{Traceability and Provenance of Assets}

Blockchain technology provides an unalterable record of the asset's history, in which both its origin and components can be evaluated, as well as all changes, updates, maintenance, and operations throughout its history. Every change made to the resource that is relevant for the ecosystem can be recorded on the blockchain, guaranteeing both the integrity of the data, and the date on which it occurred.

This traceability of assets, and the components that compose them, can also be carried out throughout the entire supply/value chain, making it possible to analyze the impact of any change in the design/composition of a product at operational level. This anticipates changes in consumption trends, avoids manually entering details of products received by suppliers, automates claims and guarantees without requiring paperwork, and, lastly, provides greater assurance in relation to certificates of origin of materials/products compared to current paper-based certificates [27].

The main industrial actors had already tried to create traceability systems before using traditional systems controlled by themselves. However, they had not been accepted by the rest of the ecosystem because nobody wanted to admit that the giant of the supply chain was also the custodian of the information of the whole chain, giving them an even more privileged position than they already had before. Therefore, blockchain offers an alternative in which all participants in the supply/value chain can create a community in which there is no privileged central entity.

In some of the evaluated projects these assets were intangible, for example, energy, where precisely the traceability of their provenance is crucial to demonstrate to customers the origin and type of energy consumed, especially in those cases where the consumer is paying for renewable energy [28].

The need to trace another typology of intangible resources such as intellectual property rights linked to digital assets of various types has also been identified [29]. In all cases, the requirements were very common, it was necessary to prove that at a certain date the asset had already been created by someone. In addition, in some cases it was necessary to trace the rights to its use/consumption [30].

The provenance issue arises precisely in several projects of traceability of both tangible and intangible goods [31,32]. Several projects focused on the origin of the materials used in the industrial or construction process were also studied, all of them linked to the circular economy $[33,34]$.

\subsubsection{Traceability/Certification of Processes and Regulatory Compliance}

Process traceability is closely linked to the previous section, as it benefits from the blockchain's ability to create an unalterable tracking that is not controlled by a single key player. However, in this case the traceability is completed over a process instead of an asset. There are cases in which there is no obvious differentiation between them, since examples can be found such as the processes of industrial transformation of an asset in which a company presents both needs. In these cases, the project must provide value in both aspects by carrying out the traceability of the item and its state, in addition to the traceability of industrial transformation process applied to the resource.

However, in general, when process traceability is mentioned, it refers to those internal or external processes to organizations that must be monitored, and in some cases certified because in some domains this is necessary for regulatory compliance. Processes linked to different domains have been identified in the literature:

- Construction and industrial transformation processes linked to quality standards or circular economy certifications [34].

- Food safety processes in a supply chain [35], sometimes also linked to the process of obtaining labels of quality, bio, and ecological.

- Compliance with personal data protection regulations such as GDPR, monitoring the access and exploitation of sensitive data [36].

- $\quad$ Traceability of financial operations for regulatory compliance [37]. 
- $\quad$ Tenders or registration of power of attorney in the public sector [38].

\subsubsection{Transparency of Processes}

Transparency is usually closely linked to traceability because if transparency is desired for suppliers, customers, or stakeholders in general, it is only necessary to give them visibility of the traceability of that process. In addition, when this traceability has been reflected in blockchain gives it more confidence to the transparency process because blockchain guarantees that the records have not been modified later to adjust them to another reality.

However, transparency is independent of the traceability of blockchain processes, as there is the possibility to offer transparency on processes that are not traced in blockchain, reflecting only the result of the process in the blockchain. Therefore, such transparency can be completed based on a blockchain process traceability or based on any other set of data on specific processes that want to be exposed, once or even periodically.

Among the evaluated projects, transparency projects in the field of e-government and healthcare have been mainly identified. Governments have always required transparency and this is precisely one of the values that blockchain brings to it [39], while in the health domain there are projects where transparency is required in clinical trials and related processes [40].

Traceability of construction processes, circular economy, or even the origin of energy, are the other applications where the need for transparency with other actors in the ecosystem was present.

\subsubsection{Shared Asset/Process Management}

Adams et al. [41] in 2003 analyzed the problem of shared asset management and defined it as: " ... the management of common pool resources can be viewed as a problem of collective action and analyzed in terms of the costs and benefits of cooperation, institutional development, and monitoring, according to variables such as group size, composition, relationship with external powers, and resource characteristics ..." .

Blockchain can solve the challenges identified in the study by providing all stakeholders with a single synchronized view of the shared resources and their states. This perfect synchronization and holistic vision can facilitate the shared management of resources, allowing to reduce frictions between the different actors, enabling complex ecosystems.

This is especially relevant in use cases where some of the parties depend on the resource status of other community participants to make decisions. In these cases, it is important to have the certainty that the information available to each actor is up to date when deciding on or performing an action, as well as having the consensus of the rest of the stakeholders so that at any given time two participants cannot execute a change in the process, or asset, that is incompatible between them; and in that case, the blockchain ensures that only one of the two simultaneous changes can take place. This happens, for example, when two participants launch a simultaneous reservation order on a shared asset. One of the two orders should be accepted, and the other should be rejected when processed by the community. Something so easy to implement in a single organization is complex in a shared resource environment, especially when a single participant is not to be trusted as a central decision-maker and coordinator of all shared resources.

Sometimes shared asset management refers to a set of actors having exactly the same visibility over the state of an item, or its history, without the possibility of being discordant.

This need has been found in the evaluated projects linked to a set of actors who need to know the status of a financial asset, a commercial/logistic transaction, authorizations to third parties to access certain information, administrative consents, shared whitelist/blacklist in threat intelligence environments, or even the status of items listed in marketplaces. 


\subsubsection{Trustworthiness and Integrity}

The decentralization of governance, as well as the integrity and immutability of blockchain transactions, make blockchain networks a "source of truth" [42]. Additionally, each participant must digitally sign every transaction they make on the blockchain, so that, in addition to agreeing with "the truth", it is recorded who is responsible for any change or evolution of that truth. This is important for possible claims among participants in case the information recorded by any of them was not entirely accurate. Therefore, blockchain is the right technology to create reliable repositories to make, and automate, decisions in companies.

There are different reasons for which a group of participants requires a common reliable source of information. The study shows cybersecurity projects that need to know with certainty attack signatures, commands, or even verify the integrity of a software/firmware or configuration to be installed [43]. Projects required a reliable source from which to automate indemnifications, technical evidence records for subsequent forensic analysis, or claims between parties [44]. Other projects required the registration of intellectual property, verifiable credentials linked to a self-sovereign identity [45], or even clinical trial results and consent from informants for further evaluation. In general, any type of information that could be used a posteriori, or even information that third parties must trust in order to automate their own processes as discussed below.

\subsubsection{Automation of Processes}

Many projects required a unique synchronized vision of the state of shared assets or resources of common interest, as well as the integrity and reliability of the information registered about those assets/processes to fully automate the decision-making processes.

It is feasible to avoid manual monitoring to automate and make decisions with the certainty that up-to-date information about a process/asset is available, and reliable, besides the fact that a third party cannot modify it for its own benefit.

Currently, companies do not rely on automating certain decisions based on information that may be published by a third party on a web service because the third party may modify such information, which could result in the company making incorrect decisions, and also not having evidence that the third party has acted in bad faith [46]. Thanks to blockchain, companies can automate decisions based on third party information, which can substantially increase the business value of the companies.

The studied projects presented cases of automation and enforcement of IT processes such as the deletion of user data in an automated way based on the user's right to be forgotten, the triggering of contingency actions for cyber security such as the isolation of an infrastructure from the internet, or the automated closure of network ports based on threat intelligence information [47]. In the industrial area, automated actions are carried out in the operations infrastructure based on information from trusted third parties registered in the blockchain without these orders having to be supervised by humans, interaction between robotic swarm systems [48], or robotic process automation in an office environment [49].

\subsubsection{Smart Contracts}

In 1994, Szabo [50] devised the term Smart Contract and defined it as: "a computerized transaction protocol that executes the terms of a contract. The general objectives of smart contract design are to satisfy common contractual conditions (such as payment terms, liens, confidentiality, and even enforcement), minimize exceptions both malicious and accidental, and minimize the need for trusted intermediaries". Sometime later, the concept of Smart Contracts was specified in more detail [51], but Smart Contracts could not be implemented until blockchain technology had been conceived. Precisely, the first programs that were designed in blockchain were the Smart Contracts. That is why today we call Smart Contracts any native blockchain program, even though this program in many cases may be executing or automating processes that are not a "contract" between two agents. When in 
this study we refer to the term Smart Contract we refer to Szabo's original concept in which there is a custody of value (tokens) in the intermediation between two or more parties.

Not surprisingly, in the analysis the need to satisfy contractual conditions between two or more agents has been found, which is one of the main and differential values of blockchain technology. Thus, among the evaluated projects we found several marketplaces of different typology (Energy, Manufacturing Industry, etc.) [52], bilateral contracts specially focused on energy [53], parametric insurance that automatically indemnifies through assets tokenized in a blockchain [54], several examples of sharing economy and prosumers [55], and automated distribution of digital intellectual property rights [30].

\subsubsection{Digital Identity}

Many ecosystems and users demand a new model of interoperable digital identity, focused and managed by the user himself, and ensuring privacy (Privacy by Design).

In 2016, Allen [56] defined the basis of a new decentralized identity model called "Self-Sovereign Identity" (SSI). This new identity concept aims to respond to the demand for a new identity based on 10 principles designed to ensure that users maintain control of their identity and do not have to rely on any central entity. Thus, users will be able to present the attributes of their identity (age, nationality, academic qualifications, etc.) to third parties minimizing the presented information using zero knowledge proofs [57] to maximize their privacy. This allows users to prove, for example, their legal age without disclosing their specific age.

In the sample of analyzed projects, typical cases have been found such as the identity of users of public services as well as other digital services (e.g., financial or health services). These are the most common in the academic literature, but we have also discovered cases of a more industrial nature in which industrial devices, or even the manufactured products themselves acquire that "I" character. They obtain an identity that enriches with parameters about their certifications regarding design, manufacturing processes, or homologations. Moreover, these identity attributes can be used in operation so that a system of systems admits the execution of a certain component, depending on the provided credentials.

\subsubsection{Sovereignty of Data and Data-Driven Services}

Governance and sovereignty of data and data-driven services is a growing need in business [58]. Today, most business data are not being exploited, nor is artificial intelligence being able to play a greater role, precisely because of the desire to have control over the data.

Companies are afraid of sharing data with third parties because once they do it they no longer have control over it, and data can be replicated and distributed without their consent, losing its economic value [59].

Unblocking this situation and valuing data is something in which blockchain, in combination with different privacy-preserving technologies such as homomorphic encryption [60], differential privacy [61], Federated Learning [62], or Secure Multi-Party Computing [63], can be decisive. In some cases, these techniques have recently been used to design a privacy-preserving contact tracing framework [64].

Precisely in this line of secure data exploitation are the analyzed projects, whose objective is to allow training of machine/deep learning models with third party data without making a disclosure of such data, third parties offering services on business data without having direct access to the information (or at least not in plain text), or simply secure data sharing managed by a digital trusted third party, that is blockchain.

\subsubsection{Machine-to-Machine (M2M) Transactions and Machine Economy}

The Machine-to-Machine (M2M) transactions and particularly the Machine Economy, or M2M Economy, is a new paradigm that emerges by transferring the sharing economy to the IoT [65]. Thanks to the capability of decentralization and tokenization of assets and services of blockchain, the Machine Economy allows the creation of a new sharing 
economy among the machines themselves; putting in as value their data/services in this ecosystem, and operating in an autonomous way with tokens [66]. Attaran et al. [67] discuss in the chapter "new business applications for the blockchain" several cases linked to M2M transactions.

The token economy [68] in the IoT field is still very novel. However, in the set of analyzed projects tokenized transactions between machines in Industrial Internet of Things (IIoT) (manufacturing and energy) can be discovered as well as other proofs of concept in the fields of autonomous vehicles.

\subsection{Blockchain Applications Impact Analysis}

The demand for each use case was studied according to different impact criteria. This will help to understand the needs of the companies, as well as to identify patterns.

The first analysis determines the investment in each of these functionalities by company size. Table 2 shows how trustworthiness and integrity is the most demanded need, it represents between $16.96 \%$ and $21.51 \%$ of the investment, depending on the size of the company. On the other hand, automation of processes is the only aspect in which some of the company sizes do not invest, specifically in the case of micro and small enterprises. This is probably because large and medium-sized companies have more complex processes where blockchain can provide greater value and justify the return on investment.

Table 2. Applications investment by company size (percentages).

\begin{tabular}{|c|c|c|c|c|c|c|c|c|c|c|c|c|}
\hline Size & $\begin{array}{c}\text { Dec. of } \\
\text { Processes }\end{array}$ & $\begin{array}{c}\text { Dec. of Buss. } \\
\text { Models }\end{array}$ & $\begin{array}{l}\text { Trac. of } \\
\text { Assets }\end{array}$ & $\begin{array}{c}\text { Trac. of } \\
\text { Processes }\end{array}$ & $\begin{array}{c}\text { Trans. of } \\
\text { Processes }\end{array}$ & $\begin{array}{c}\text { Shared Asset } \\
\text { Mgmt. }\end{array}$ & $\begin{array}{l}\text { Trust and } \\
\text { Integrity }\end{array}$ & $\begin{array}{c}\text { Autom. of } \\
\text { Processes }\end{array}$ & $\begin{array}{c}\text { Smart } \\
\text { Contracts }\end{array}$ & $\begin{array}{c}\text { Digital } \\
\text { Identity }\end{array}$ & $\begin{array}{c}\text { Sovereignty } \\
\text { Data }\end{array}$ & $\begin{array}{l}\text { Machine } \\
\text { Economy }\end{array}$ \\
\hline Micro & 14.96 & 9.16 & 4.60 & 9.92 & 2.12 & 4.28 & 16.96 & - & 5.81 & 12.11 & 9.50 & 10.58 \\
\hline Small & 8.11 & 2.44 & 8.03 & 13.00 & 4.11 & 8.04 & 21.53 & - & 5.34 & 13.11 & 8.11 & 8.17 \\
\hline Med. & 8.50 & 1.49 & 6.36 & 15.33 & 3.23 & 12.04 & 17.32 & 5.91 & 5.53 & 9.61 & 6.42 & 8.25 \\
\hline Large & 15.14 & 2.45 & 6.45 & 7.23 & 1.89 & 5.22 & 21.51 & 11.03 & 1.13 & 14.32 & 4.20 & 9.42 \\
\hline
\end{tabular}

Micro enterprises are most active investing in the decentralization of business processes and Machine Economy, although with less difference compared to other company sizes. Micro and large companies are investing in the decentralization of processes, in contrast to small and medium-sized companies that mainly invest in traceability of processes. We can observe how medium-sized companies are the most active investors in shared asset management; and large companies stand out for their investment in process automation and limited investment in Smart Contracts.

Table 3 presents the percentage of investment made by sector in each of the identified applications. The construction sector is mainly investing in process traceability, shared asset management, and trustworthiness. No investments have been identified in more decentralized characteristics such as process decentralization, business models, smart contracts, or Machine Economy.

Table 3. Applications investment by sector (percentages).

\begin{tabular}{|c|c|c|c|c|c|c|c|c|c|c|c|c|}
\hline Sector & $\begin{array}{c}\text { Dec. of } \\
\text { Processes }\end{array}$ & $\begin{array}{l}\text { Dec. of Buss. } \\
\text { Models }\end{array}$ & $\begin{array}{l}\text { Trac. of } \\
\text { Assets }\end{array}$ & $\begin{array}{c}\text { Trac. of } \\
\text { Processes }\end{array}$ & $\begin{array}{c}\text { Trans. of } \\
\text { Processes }\end{array}$ & $\begin{array}{c}\text { Shared Asset } \\
\text { Mgmt. }\end{array}$ & $\begin{array}{l}\text { Trust and } \\
\text { Integrity }\end{array}$ & $\begin{array}{c}\text { Autom. of } \\
\text { Processes }\end{array}$ & $\begin{array}{c}\text { Smart } \\
\text { Contracts }\end{array}$ & $\begin{array}{c}\text { Digital } \\
\text { Identity }\end{array}$ & $\begin{array}{c}\text { Sovereignty } \\
\text { Data }\end{array}$ & $\begin{array}{l}\text { Machine } \\
\text { Economy }\end{array}$ \\
\hline Cons. & - & - & 10.78 & 22.21 & 10.78 & 22.21 & 22.21 & 6.51 & - & 5.31 & - & - \\
\hline eGov & 9.93 & - & - & 24.34 & 5.26 & 24.34 & 13.98 & 1.75 & - & 16.04 & 4.35 & - \\
\hline Energ. & 3.74 & 4.23 & 15.42 & 15.38 & 1.68 & 13.77 & 15.79 & 10.77 & 3.82 & - & - & 15.42 \\
\hline $\begin{array}{l}\text { Enan. } \\
\text { Finan. }\end{array}$ & $\begin{array}{l}0.74 \\
0.69\end{array}$ & $\begin{array}{l}.23 \\
1.38\end{array}$ & $\begin{array}{l}15.42 \\
0.69\end{array}$ & $\begin{array}{l}15.38 \\
22.14\end{array}$ & $\begin{array}{l}1.68 \\
8.46\end{array}$ & 22.83 & $\begin{array}{l}15.79 \\
10.49\end{array}$ & $\begin{array}{l}10.17 \\
22.14\end{array}$ & $\begin{array}{l}3.82 \\
11.18\end{array}$ & - & 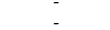 & 13.42 \\
\hline Ind4.0 & 4.08 & 0.90 & 4.31 & 4.66 & 0.79 & 10.79 & 20.90 & 10.57 & $\begin{array}{l}1.83 \\
\text { s. }\end{array}$ & 6.44 & 15.84 & 18.89 \\
\hline Health & $\begin{array}{l}4.00 \\
13.53\end{array}$ & 5.89 & 5.90 & $\begin{array}{c}.400 \\
12.39\end{array}$ & - & 17.88 & 17.88 & 5.19 & 1.00 & $\begin{array}{r}0.44 \\
12.69\end{array}$ & 8.64 & - \\
\hline Mobil. & 11.20 & 6.81 & 7.99 & 7.99 & 3.60 & 14.80 & 14.80 & 14.80 & - & 11.20 & - & 6.81 \\
\hline ICT & 9.03 & 1.94 & 2.25 & 7.35 & 0.33 & 4.34 & 17.64 & 10.29 & 3.48 & 19.23 & 11.75 & 12.36 \\
\hline
\end{tabular}

Governments are mainly investing in process traceability and shared asset management, followed by digital identity for their citizens and decentralization of processes. Furthermore, it is one of the few sectors that is not investing in asset traceability.

The energy sector is heavily investing in process and asset traceability, as well as process automation to improve its current processes. In addition, due to the decentralization of power generation and emerging prosumers [69], the energy sector is investing in trust and integrity, shared asset management, and Machine Economy. 
The financial industry is focused on improving its current processes, with most of its investment focused on shared asset management, process automation, and traceability. Precisely, because the disintermediation of financial relations could jeopardize its medium/long-term business viability, there is no investment in the decentralization of processes.

The fourth industrial revolution is reflected in the industrial investments that have trust and integrity of relationships at their core, as well as industrial data sovereignty and Machine Economy. In a second tier, shared asset management and process automation could be highlighted.

The health sector invests mainly in shared resource management, digital identity, and trust, with traceability and decentralization of processes in a secondary plane. All this fits with a more patient-centric vision in which health services aim to interoperate and empower the user over their health data.

In the case of mobility, we should note that they mainly invest in shared asset management, digital identity, and trust, but in this case their commitment is linked to process automation rather than process decentralization.

The ICT sector stands out for its clear commitment to digital identity and trust, which aims to change the identity model towards a Self-Sovereign Identity (SSI), followed by data sovereignty and Machine Economy linked to the data economy and IoT ecosystem.

Finally, Figure 3 shows the investment made in each of the applications identified in the study. Evaluated projects indicate a higher investment in trustworthiness of data and relationships between different stakeholders. This characteristic represents $18 \%$ of global investment.

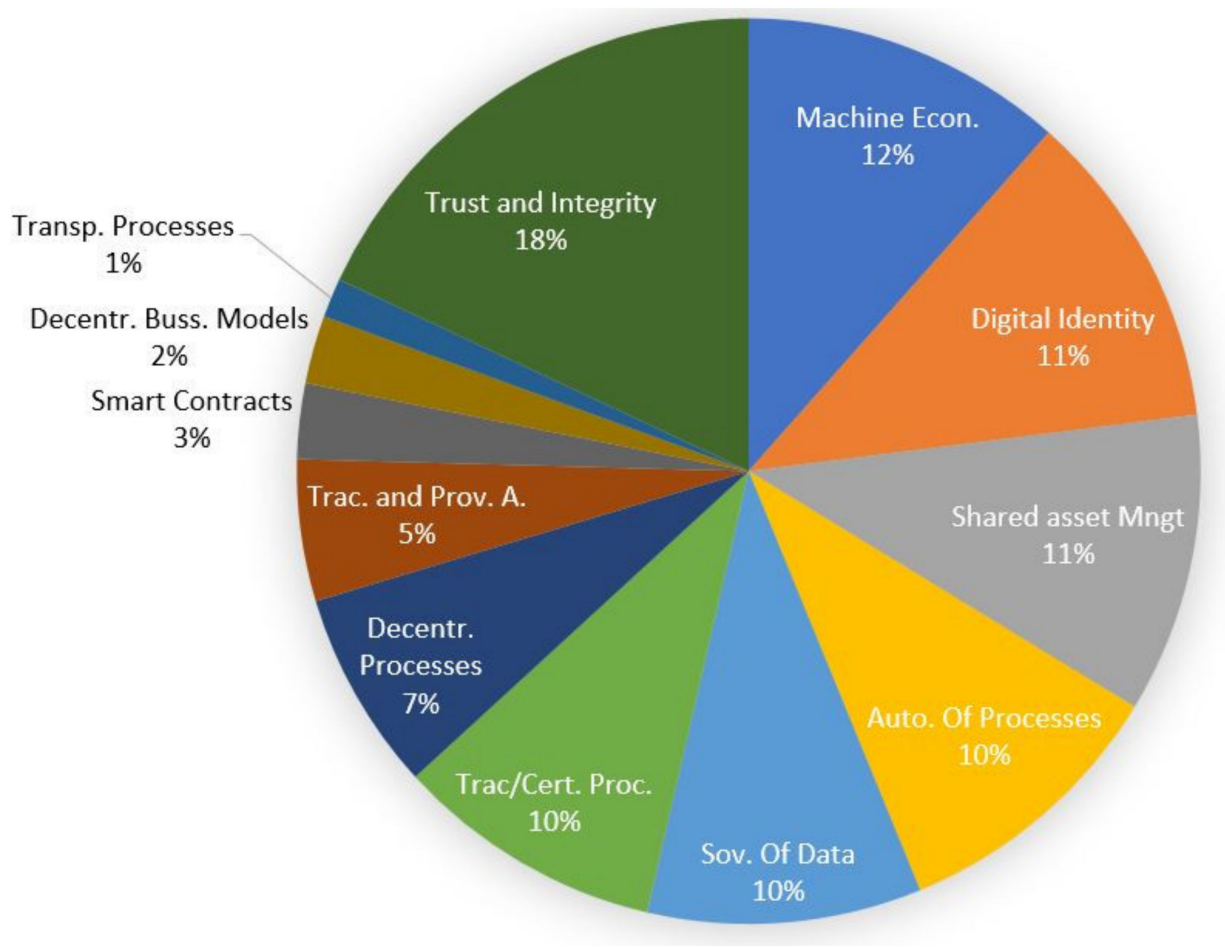

Figure 3. Blockchain investment distribution by business value.

Machine Economy is the next value with the highest investment. This distinctive IoT trend, both for consumer and industrial applications, represents $12 \%$ of global investment; probably driven by the high investment in ICT and Industry 4.0 projects, as shown in Figure 1. The next most heavily invested business values are Digital Identity and Shared Asset Management, each representing 11\% of global blockchain investment. These four business applications together account for $56 \%$ of the overall analyzed investment. 
Surprisingly, the three functionalities that have received the least investment are process transparency, decentralization of business models, and smart contracts. Together, they represent only $6 \%$ of the analyzed investment, followed by asset traceability which represents just $5 \%$ of the investment. These features are some of the most frequently mentioned in the studies reviewed in the introduction, but they are not the ones in which companies are making their main investments. We will analyze this fact in the conclusions.

\subsection{Relational Model of Blockchain Provided Value}

After discussing the business value and impact that blockchain technology offers to companies, the next step was to analyze if there is any relationship between the demands of these functionalities. That is, the relationship between the investment in these functional values by companies in their projects, to infer if there is a relationship between them.

For this purpose, a clustering analysis using a hierarchical cluster was carried out [70]. To perform the analysis, we associated with each busines application a 104-tuple vector, corresponding to the 104 projects examined in this paper. Each component was assigned the worth 1 if the functionality was present in the purposes of the project, and 0 otherwise. Then, we used the squared Euclidean distance as a measure of the relationship between the applications. In this way, we obtained a dendrogram (Figure 4) where we can appreciate the relationship between the different functional values of the blockchain technology in the analyzed projects [71]. Different cluster sizes were explored and it was decided to establish a cluster of six since it is the one with more coherence.

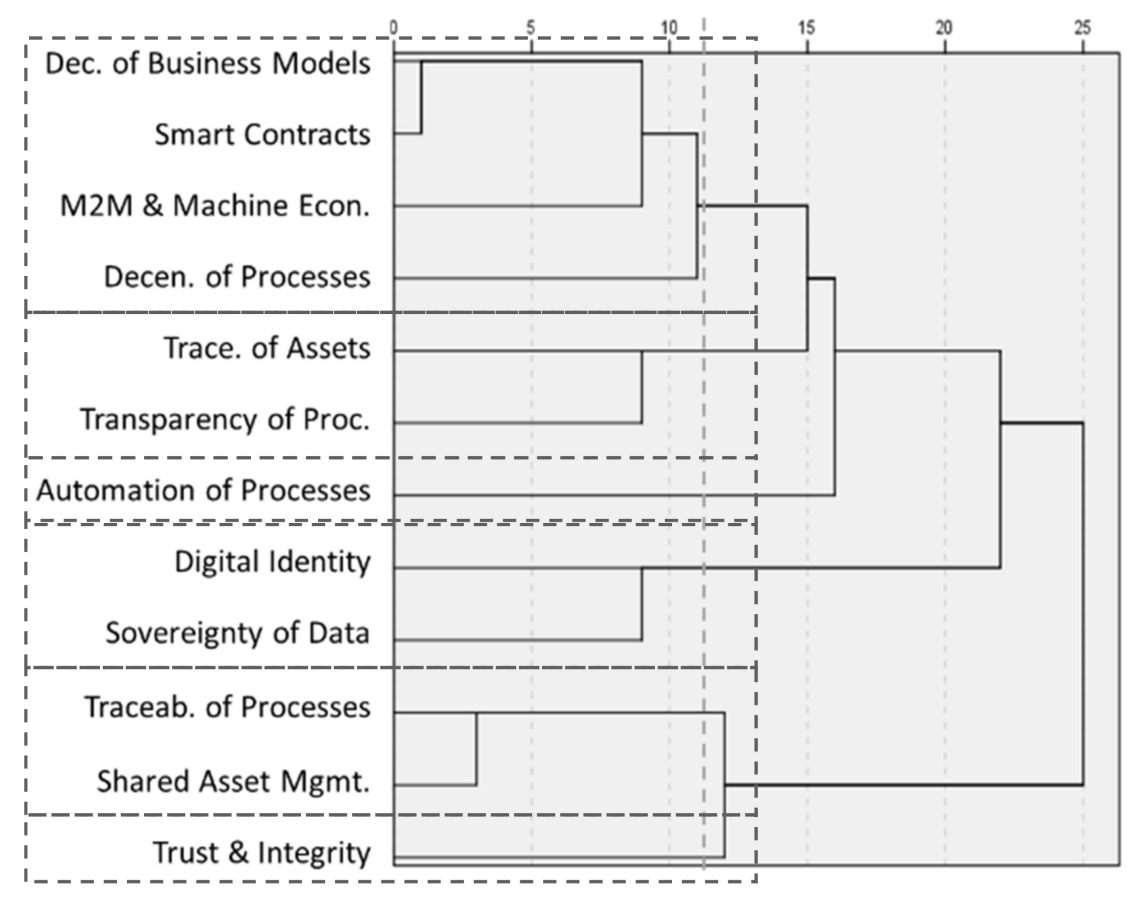

Figure 4. Hierarchical clustering dendrogram using an average linkage between groups (rescaled distance).

The dendrogram shows clear relationships between the decentralization of business models and smart contracts. The result is natural since one of the most common ways of creating decentralized businesses is through a Decentralized Autonomous Organization (DAO) which is based on a smart contract that governs the organization [72]. In the case of M2M transactions and Machine Economy, it is clearly related to the above as it is a decentralization of the current IoT business models through smart contracts. The fourth value in the first cluster is process decentralization, which is also found when business models are decentralized. 
Traceability and provenance of assets is a highly demanded value in transparency projects, that is why these two variables are closely related in many of the analyzed projects. These two characteristics represent the second cluster.

Something similar occurs with the traceability of processes and the management of shared assets, which are closely related and form a cluster. The reason for this is that many of the shared asset management projects we analyzed also required traceability of the processes performed on those shared assets.

Digital identity and data sovereignty are also closely linked and form a cluster, since in order to create data sovereignty systems it is common to use a decentralized identity on the basis of which to implement policies related to data consumption.

Finally, it should be noted that there are two factors that are not so closely related with others and, therefore, each one forms a cluster on its own. These characteristics are Trustworthiness and Integrity and Automation of Processes.

\section{Conclusions}

More than 100 real blockchain contracts were analyzed to answer the re-search question of what blockchain functional values companies are investing in, regardless of the sector and use case. The research was completed based on a systematic analysis of actual company investments rather than theoretical benefits of the technology. Based on the documentation of analyzed projects, the real needs of the companies regarding blockchain were identified, classified, and correlated.

Our findings allow us to obtain the real value of blockchain for companies, since until then the literature only had specific use cases or reviews of potential blockchain applications, but in no case a review and analysis based on a set of real projects in which companies have invested. In addition, the article shows the relationship between these identified values, allowing a clustering of six elements since many of the values are demanded jointly. The study will allow to identify new applications of the blockchain technology in scenarios that have not yet been identified, increasing the adoption of blockchain technology.

On the other hand, the study shows that three of the most promising values of blockchain technology are the ability to decentralize processes, business models, and the creation of smart contracts. However, we found that combined they only represent $6 \%$ of the actual investment in blockchain. We discovered that companies are mainly demanding trustworthiness of their information, Machine Economy, digital identity, and shared asset management which together account for more than half of the economic investment of companies in blockchain technology. This might indicate that companies are making pragmatic decisions and are in a process of learning. This may be representative of the fact that we are still in the early stages of blockchain technology adoption, and that companies need to learn about the technology before undertaking investments of greater uncertainty or risk.

\subsection{Limitations}

Although the results of the study are very promising and show that companies are starting to invest in blockchain technology, the reader should be aware that blockchain technology still presents different challenges at the technological level [73-75].

On the other hand, our own study also has limitations. The authors consider that the sample of 104 contracts in the most relevant industries is sufficiently representative; actually, a larger sample could only slightly vary the results. Likewise, the sample may also present some geographic bias since the investments are mostly from European companies.

We are at a very early stage in the adoption and deployment of blockchain technology. In the coming years, researchers may identify new uses of the technology that we do not know of today. These new uses may also represent part of the investment of companies in the coming years. 


\subsection{Future Research}

Because this analysis of investment in blockchain technology was carried out independently of its specific uses, this study can help to identify new applications of this technology that have not been yet considered in the literature. Thus, expert researchers in different domains will be able to use the present manuscript as a basis for their reflection and identify new applications of blockchain technology in their field of expertise.

On the other hand, the work identified that although decentralization of business models currently only represents $2 \%$ of investment, all sectors, except construction and governments, are beginning to invest in it; this can represent a great risk to current models, such as the aforementioned platform business model.

Therefore, another research line opened by this research is to explore how blockchain technology will decentralize and disrupt current business models, and what kind of new decentralized business models will emerge.

Author Contributions: Conceptualization, O.L., M.S.-S. and J.M.Z.; methodology, O.L., M.S.-S. and J.M.Z.; formal analysis, O.L. and J.M.Z.; investigation, O.L. and M.S.-S.; resources, O.L. and M.S.-S.; data curation, O.L.; writing-original draft preparation, O.L.; writing-review and editing, O.L., M.S.-S. and J.M.Z.; supervision, M.S.-S. and J.M.Z.; funding acquisition, J.M.Z. All authors have read and agreed to the published version of the manuscript.

Funding: This research was funded by Spanish Ministry of Science and Innovation, grant number PID2019- 105291GB-I00; and by The Basque Country University, grant number GIU20/019.

Institutional Review Board Statement: Not applicable.

Informed Consent Statement: Not applicable.

Conflicts of Interest: The authors declare no conflict of interest.

\section{References}

1. Nakamoto, S. Bitcoin: A Peer-to-Peer Electronic Cash System; 2008; Available online: https://bitcoin.org/bitcoin.pdf (accessed on 17 December 2021).

2. Fanning, K.; Centers, D.P. Blockchain and Its Coming Impact on Financial Services. J. Corp. Account. Financ. 2016, 27, 53-57. [CrossRef]

3. Collomb, A.; Sok, K. Blockchain/distributed ledger technology (DLT): What impact on the financial sector? Digiworld Econ. J. 2016, 103, 93-111.

4. Mettler, M. Blockchain technology in healthcare: The revolution starts here. In Proceedings of the 2016 IEEE 18th International Conference on e-Health Networking, Applications and Services (Healthcom), Munich, Germany, 14-16 September 2016; IEEE: New York, NY, USA, 2016; pp. 1-3.

5. Ekblaw, A.; Azaria, A.; Halamka, J.D.; Lippman, A. A Case Study for Blockchain in Healthcare: "MedRec" prototype for electronic health records and medical research data. In Proceedings of the IEEE Open \& Big Data Conference, Los Alamitos, CA, USA, 15-18 December 2021; p. 13.

6. Wang, L.; Xie, Y.; Zhang, D.; Liu, J.; Jiang, S.; Zhang, Y.; Li, M. Credible Peer-to-Peer Trading with Double-Layer Energy Blockchain Network in Distributed Electricity Markets. Electronics 2021, 10, 1815. [CrossRef]

7. Huang, Z.; Li, Z.; Lai, C.S.; Zhao, Z.; Wu, X.; Li, X.; Tong, N.; Lai, L.L. A novel power market mechanism based on blockchain for electric vehicle charging stations. Electronics 2021, 10, 307. [CrossRef]

8. Ølnes, S. Beyond bitcoin-Public sector innovation using the bitcoin blockchain technology. In Proceedings of the Norsk Konferanse for Organisasjoners Bruk at IT, Oslo, Norway, 19-21 November 2015.

9. Deloitte's 2020 Goblal Blockchain Survey. Available online: https://www2.deloitte.com/content/dam/insights/us / articles/66 08_2020-global-blockchain-survey/DI_CIR\%202020\%20global\%20blockchain\%20survey.pdf (accessed on 7 December 2021).

10. Seebacher, S.; Schüritz, R. Blockchain technology as an enabler of service systems: A structured literature review. In Proceedings of the International Conference on Exploring Services Science, Rome, Italy, 24-26 May 2017; pp. 12-23.

11. Tama, B.A.; Kweka, B.J.; Park, Y.; Rhee, K.H. A critical review of blockchain and its current applications. In Proceedings of the 2017 International Conference on Electrical Engineering and Computer Science (ICECOS), Sriwijaya, Indonesia, 22-23 August 2017; 2017; pp. 109-113.

12. Hawlitschek, F.; Notheisen, B.; Teubner, T. The limits of trust-free systems: A literature review on blockchain technology and trust in the sharing economy. Electron. Commer. Res. Appl. 2018, 29, 50-63. [CrossRef]

13. Casino, F.; Dasaklis, T.K.; Patsakis, C. A systematic literature review of blockchain-based applications: Current status, classification and open issues. Telemat. Inform. 2019, 36, 55-81. [CrossRef] 
14. Laroiya, C.; Saxena, D.; Komalavalli, C. Applications of blockchain technology. In Handbook of Research on Blockchain Technology; Academic Press: Cambridge, MA, USA, 2020; pp. 213-243.

15. Perera, S.; Nanayakkara, S.; Rodrigo, M.N.N.; Senaratne, S.; Weinand, R. Blockchain technology: Is it hype or real in the construction industry? J. Ind. Inf. Integr. 2020, 17, 100125. [CrossRef]

16. Ko, T.; Lee, J.; Ryu, D. Blockchain technology and manufacturing industry: Real-time transparency and cost savings. Sustainability 2018, 10, 4274. [CrossRef]

17. Casado-Vara, R.; Chamoso, P.; De la Prieta, F.; Prieto, J.; Corchado, J.M. Non-linear adaptive closed-loop control system for improved efficiency in IoT-blockchain management. Inf. Fusion 2019, 49, 227-239. [CrossRef]

18. Zheng, Z.; Xie, S.; Dai, H.; Wang, H. An overview of blockchain technology: Architecture, consensus, and future trends. In Proceedings of the 2017 IEEE International Congress on Big Data, Honolulu, HI, USA, 25-30 June 2017; pp. 557-564.

19. Mendling, J.; Weber, I.; Aalst, W.V.D.; Brocke, J.V.; Cabanillas, C.; Daniel, F.; Debois, S.; Di Chiccio, C.; Dumas, M.; Dustar, S.; et al. Blockchains for business process management-challenges and opportunities. ACM Trans. Manag. Inf. Syst. 2018, 9, 1-16. [CrossRef]

20. Harmon, P. Business Process Change: A Business Process Management Guide for Managers and Process Professionals; Morgan Kaufmann: Burlington, VT, USA, 2019.

21. Caldara, D.; Iacoviello, M. Measuring geopolitical risk. FRB Int. Financ. Discuss. Pap. 2018, 2018, 1222. [CrossRef]

22. Nowiński, W.; Kozma, M. How can blockchain technology disrupt the existing business models? Entrep. Bus. Econ. Rev. 2017, 5, 173-188. [CrossRef]

23. Lage, O.; Saiz-Santos, M. Blockchain and the decentralisation of the cybersecurity Industry. DYNA 2021, 96, 239. [CrossRef]

24. Morkunas, V.J.; Paschen, J.; Boon, E. How blockchain technologies impact your business model. Bus. Horiz. 2019, 62, 295-306. [CrossRef]

25. Täuscher, K.; Laudien, S.M. Understanding platform business models: A mixed methods study of marketplaces. Eur. Manag. J. 2018, 36, 319-329. [CrossRef]

26. Stoletov, N. Uberisation Business Model Based on Blockchain for Implementation Decentralized Application for Lease/Rent Lodging. In Proceedings of the Information Systems and Technologies to Support Learning: Proceedings of EMENA-ISTL, Fez, Morocco, 25-27 October 2018; Volume 111, p. 225.

27. Mezquita, Y.; Casado-Vara, R.; González Briones, A.; Prieto, J.; Corchado, J.M. Blockchain-based architecture for the control of logistics activities: Pharmaceutical utilities case study. Log. J. IGPL 2021, 29, 974-985. [CrossRef]

28. Andoni, M.; Robu, V.; Flynn, D.; Abram, S.; Geach, D.; Jenkins, D.; McCAllum, P.; Peacock, A. Blockchain technology in the energy sector: A systematic review of challenges and opportunities. Renew. Sustain. Energy Rev. 2019, 100, 143-174. [CrossRef]

29. Ito, K.; O'dair, M. A Critical Examination of the Application of Blockchain Technology to Intellectual Property Management. In Business Transformation through Blockchain; Palgrave Macmillan: Cham, Switzerland, 2019; pp. 317-335.

30. Finck, M.; Moscon, V. Copyright Law on Blockchains: Between New Forms of Rights Administration and Digital Rights Management 2.0. IIC-Int. Rev. Intellect. Prop. Compet. Law 2019, 50, 77-108. [CrossRef]

31. Montecchi, M.; Plangger, K.; Etter, M. It's real, trust me! Establishing supply chain provenance using blockchain. Bus. Horiz. 2019, 62, 283-293. [CrossRef]

32. Kouhizadeh, M.; Sarkis, J.; Zhu, Q. At the nexus of blockchain technology, the circular economy, and product deletion. Appl. Sci. 2019, 9, 1712. [CrossRef]

33. Hatzivasilis, G.; Ioannidis, S.; Fysarakis, K.; Spanoudakis, G.; Papadakis, N. The green blockchains of circular economy. Electronics 2021, 10, 2008. [CrossRef]

34. Shih, C.S.; Yang, K.W. Design and implementation of distributed traceability system for smart factories based on blockchain technology. In Proceedings of the Conference on Research in Adaptive and Convergent Systems, Chongqing, China, 24-27 September 2019; 2019; pp. 181-188.

35. Caro, M.P.; Ali, M.S.; Vecchio, M.; Giaffreda, R. Blockchain-based traceability in Agri-Food supply chain management: A practical implementation. In Proceedings of the 2018 IoT Vertical and Topical Summit on Agriculture-Tuscany (IOT Tuscany), Tuscany, Italy, 8-9 May 2018; IEEE: Piscataway, NJ, USA, 2018; pp. 1-4.

36. Compert, C.; Luineti, M.; Portier, B. Blockchain and GDPR: How blockchain could address five areas associated with GDPR compliance. IBM Secur. White Pap. 2018. Available online: https://iapp.org/media/pdf/resource_center/blockchain_and_gdpr. pdf (accessed on 17 December 2021).

37. YOO, S. Blockchain based financial case analysis and its implications. Asia Pac. J. Innov. Entrep. 2017, 11, 312-321. [CrossRef]

38. Ølnes, S.; Ubacht, J.; Janssen, M. Blockchain in government: Benefits and implications of distributed ledger technology for information sharing. Gov. Inf. Q. 2017, 34, 355-364. [CrossRef]

39. Batubara, F.R.; Ubacht, J.; Janssen, M. Challenges of blockchain technology adoption for e-government: A systematic literature review. In Proceedings of the 19th Annual International Conference on Digital Government Research: Governance in the Data Age, Delft, The Netherlands, 30 May-1 June 2018; 2018; pp. 1-9.

40. Nugent, T.; Upton, D.; Cimpoesu, M. Improving data transparency in clinical trials using blockchain smart contracts. F1000Research 2016, 5, 2541. [CrossRef]

41. Adams, W.M.; Brockington, D.; Dyson, J.; Vira, B. Managing tragedies: Understanding conflict over common pool resources. Science 2003, 302, 1915-1916. [CrossRef] 
42. Böhme, R.; Christin, N.; Edelman, B.; Moore, T. Bitcoin: Economics, technology, and governance. J. Econ. Perspect. 2015, 29, 213-238. [CrossRef]

43. Serrano, O.L.; de Diego, S.D.D.; Seco, I.; Larrucea, X. Semi-real-time Hash Comparison for Detecting Intrusions Using Blockchain. In Proceedings of the International Conference on Model and Data Engineering, Touluse, France, 28-31 October 2019; Springer: Cham, Switzerland, 2019; pp. 165-179.

44. Ryu, J.H.; Sharma, P.K.; Jo, J.H.; Park, J.H. A blockchain-based decentralized efficient investigation framework for IoT digital forensics. J. Supercomput. 2019, 75, 4372-4387. [CrossRef]

45. Ferdous, M.S.; Chowdhury, F.; Alassafi, M.O. In search of self-sovereign identity leveraging blockchain technology. IEEE Access 2019, 7, 103059-103079. [CrossRef]

46. Ter Hofstede, A.H.; Van der Aalst, W.M.; Adams, M.; Russell, N. (Eds.) Modern Business Process Automation: YAWL and Its Support Environment; Springer Science \& Business Media: Berlin, Germany, 2009; p. 492.

47. De Diego, S.; Gonçalves, C.; Lage, O.; Manshell, J.; Kontoulis, M.; Moustakidis, S.; Guerra, B.; Liapis, A. Blockchain-Based Threat Registry Platform. In Proceedings of the 2019 IEEE 10th Annual Information Technology, Electronics and Mobile Communication Conference (IEMCON), Vancouver, BC, Canada, 17-19 October 2019; IEEE: Piscataway, NJ, USA, 2019; pp. 892-898.

48. Ferrer, E.C. The blockchain: A new framework for robotic swarm systems. In Proceedings of the Future Technologies Conference, Vancouver, BC, Canada, 15-16 November 2018; Springer: Cham, Switzerland, 2018; pp. 1037-1058.

49. Van der Aalst, W.M.; Bichler, M.; Heinzl, A. Robotic process automation. Bus. Inf. Syst. Eng. 2018, 60, 269-272. [CrossRef]

50. Szabo, N. Smart Contracts; 1994; Unpublished manuscript.

51. Szabo, N. Smart contracts: Building blocks for digital markets. EXTROPY J. Transhumanist Thought 1996, 16, 18-20.

52. Subramanian, H. Decentralized blockchain-based electronic marketplaces. Commun. ACM 2017, 61, 78-84. [CrossRef]

53. Van Leeuwen, G.; AlSkaif, T.; Gibescu, M.; van Sark, W. An integrated blockchain-based energy management platform with bilateral trading for microgrid communities. Appl. Energy 2020, 263, 114613. [CrossRef]

54. Gatteschi, V.; Lamberti, F.; Demartini, C.; Pranteda, C.; Santamaría, V. Blockchain and smart contracts for insurance: Is the technology mature enough? Future Internet 2018, 10, 20. [CrossRef]

55. Pazaitis, A.; De Filippi, P.; Kostakis, V. Blockchain and value systems in the sharing economy: The illustrative case of Backfeed. Technol. Forecast. Soc. Change 2017, 125, 105-115. [CrossRef]

56. Allen, C. The path to self-sovereign identity. Life Alacrity. 2016. Available online: http://www.lifewithalacrity.com/2016/04/thepath-to-self-soverereign-identity.html (accessed on 17 December 2021).

57. Goldreich, O.; Oren, Y. Definitions and properties of zero-knowledge proof systems. J. Cryptol. 1994, 7, 1-32. [CrossRef]

58. Jarke, M. Data Sovereignty and Data Space Ecosystems. Bus. Inf. Syst. Eng. 2019, 61, 549-550. [CrossRef]

59. Harris, D.; Khan, L.; Paul, R.; Thuraisingham, B. Standards for secure data sharing across organizations. Comput. Stand. Interfaces 2007, 29, 86-96. [CrossRef]

60. Naehrig, M.; Lauter, K.; Vaikuntanathan, V. Can homomorphic encryption be practical? In Proceedings of the 3rd ACM Workshop on Cloud Computing Security Workshop, Chicago, IL, USA, 21 October 2011; pp. 113-124.

61. Park, Y.H.; Kim, Y.; Shim, J. Blockchain-Based Privacy-Preserving System for Genomic Data Management Using Local Differential Privacy. Electronics 2021, 10, 3019. [CrossRef]

62. Peng, Z.; Xu, J.; Chu, X.; Gao, S.; Yao, Y.; Gu, R.; Tang, Y. Vfchain: Enabling verifiable and auditable federated learning via blockchain systems. IEEE Trans. Netw. Sci. Eng. 2021, 9, 173-186. [CrossRef]

63. Du, W.; Atallah, M.J. Secure multi-party computation problems and their applications: A review and open problems. In Proceedings of the 2001 Workshop on New Security Paradigms, Cloudcroft, NM, USA, 10-13 September 2001; pp. 13-22. [CrossRef]

64. Peng, Z.; Xu, C.; Wang, H.; Huang, J.; Xu, J.; Chu, X. P2B-Trace: Privacy-Preserving Blockchain-based Contact Tracing to Combat Pandemics. In Proceedings of the 2021 International Conference on Management of Data, Xi'an, China, 20-25 June 2021; pp. 2389-2393.

65. Lage, O. Blockchain: From Industry 4.0 to the Machine Economy. In Computer Security Threats; IntechOpen: London, UK, 2019.

66. Chen, Y. Blockchain tokens and the potential democratization of entrepreneurship and innovation. Bus. Horiz. 2018, 61, 567-575. [CrossRef]

67. Attaran, M.; Gunasekaran, A. Applications of Blockchain Technology in Business: Challenges and Opportunities; Springer Nature: Berlin, Germany, 2019

68. Lee, J.Y. A decentralized token economy: How blockchain and cryptocurrency can revolutionize business. Bus. Horiz. 2019, 62, 773-784. [CrossRef]

69. Morstyn, T.; Farrell, N.; Darby, S.J.; McCulloch, M.D. Using peer-to-peer energy-trading platforms to incentivize prosumers to form federated power plants. Nat. Energy 2018, 3, 94-101. [CrossRef]

70. Ziberna, A.; Kejzar, N.; Golob, P. A comparison of different approaches to hierarchical clustering of ordinal data. Metodoloski Zv. 2004, 1, 57. [CrossRef]

71. Forina, M.; Armanino, C.; Raggio, V. Clustering with dendrograms on interpretation variables. Anal. Chim. Acta 2002, 454, 13-19. [CrossRef]

72. Norta, A. Designing a smart-contract application layer for transacting decentralized autonomous organizations. In Proceedings of the International Conference on Advances in Computing and Data Sciences, Ghaziabad, India, 11-12 November 2016; pp. 595-604. 
73. Hughes, L.; Dwivedi, Y.K.; Misra, S.K.; Rana, N.P.; Raghavan, V.; Akella, V. Blockchain research, practice and policy: Applications, benefits, limitations, emerging research themes and research agenda. Int. J. Inf. Manag. 2019, 49, 114-129. [CrossRef]

74. Wu, H.; Peng, Z.; Guo, S.; Yang, Y.; Xiao, B. VQL: Efficient and Verifiable Cloud Query Services for Blockchain Systems. IEEE Trans. Parallel Distrib. Syst. 2021, 33, 1393-1406. [CrossRef]

75. Frizzo-Barker, J.; Chow-White, P.A.; Adams, P.R.; Mentanko, J.; Ha, D.; Green, S. Blockchain as a disruptive technology for business: A systematic review. Int. J. Inf. Manag. 2020, 51, 102029. [CrossRef] 